\title{
Inflammation During Virus Infection: Swings and Roundabouts
}

\author{
Sankar Bhattacharyya
}

\begin{abstract}
Inflammation constitutes a concerted series of cellular and molecular responses that follow disturbance of systemic homeostasis, by either toxins or infectious organisms. Leukocytes modulate inflammation through production of secretory mediators, like cytokines and chemokines, which work in an autocrine and/or paracrine manner. These mediators can either promote or attenuate the inflammatory response and depending on differential temporal and spatial expression play a crucial role in the outcome of infection. Even though the objective is clearance of the pathogen with minimum damage to host, the pathogenesis of multiple human pathogenic viruses has been suggested to emanate from a dysregulation of the inflammatory response, sometimes with fatal consequences. This review discusses the nature and the outcome of inflammatory response, which is triggered in the human host subsequent to infection by single-sense plus-strand RNA viruses. In view of such harmful effects of a dysregulated inflammatory response, an exogenous regulation of these reactions by either interference or supplementation of critical regulators has been suggested. Currently multiple such factors are being tested for their beneficial and adverse effects. A successful use of such an approach in diseases of viral etiology can potentially protect the affected individual without directly affecting the virus life cycle. Further, such approaches whenever applicable would be useful in mitigating death and/or debility that is caused by the infection of those viruses which have proven particularly difficult to control by either prophylactic vaccines and/or therapeutic strategies using specific antiviral drugs.
\end{abstract}

\footnotetext{
S. Bhattacharyya $(\bowtie)$

Vaccine and Infectious Disease Research Centre, Translational Health Science and Technology Institute, Faridabad, Haryana, India

e-mail: sankar@thsti.res.in
} 


\section{Keywords}

Inflammation $\cdot$ RNA virus $\cdot$ Cytokine therapy

\subsection{Introduction}

The mammalian immune system has evolved arsenal and strategies to make a distinction between microbes that are either beneficial or benign or bad, an integral part of which is differential treatment of "self" and "non-self." Whereas recognition of "self" as "non-self" can cause autoimmunity, the converse results in microbial colonization. In fact the human gut does harbor multiple variety of microbes as natural part of the biological ecosystem (Scarpellini et al. 2015). The recognized non-self are counteracted by adaptive and innate effectors of the immune system, using dedicated cells and biochemicals, which attempt to restrict the growth and impede colonization by the pathogen. The innate response is nonspecific, while the secondary adaptive response is specific for the pathogen or closely related species. The cellular component includes innate immune cells like the monocytes/macrophages, neutrophils, and natural killer (NK) cells and adaptive immune cells like B- and T-lymphocytes, which coordinate for an effective response. Cytokines are a dedicated group of biochemicals involved in this coordination and include interferons (IFNs), interleukins (ILs), and chemokines that are responsible for synchronizing the initiation, regulation, and termination of an immune response. A group $(\sim 100)$ of small polypeptides $(<20 \mathrm{kDa})$ produced predominantly although not exclusively by immune cells like macrophages and lymphocytes, cytokines are secreted out exerting their function by engaging respective cell-surface receptors and depending on biological function are labeled as either pro-inflammatory (PIC) or antiinflammatory (AIC) cytokines (Turner et al. 2014). On the one hand, several cytokines are functionally redundant, and on the other hand, some cells can express receptors for multiple cytokines.

\subsection{The Positive-Sense Single-Stranded RNA Viruses}

Viruses with positive-sense single-stranded RNA as genome can either be enveloped (Togaviridae, Flaviviridae, and Coronaviridae) or non-enveloped (Astroviridae, Caliciviridae, and Picornaviridae), and several from either group cause severe human pathology (Fields et al. 2013). Entry into human host can be by diverse means including mucosal contact (gut in enteroviruses) or vectorial inoculation (e.g., in dengue and JEV) or parenteral blood transfer (e.g., hepatitis C virus). Immobilization by interaction with extracellular matrix components like glycosaminoglycan is followed by tropism determinant cognate receptor-mediated entry (Chen et al. 1997; Olenina et al. 2005; Tan et al. 2013). In enveloped viruses, the envelope fuses with the endosomal membrane, while non-enveloped viruses breach the membrane of either the cell or the endosome using specific cofactors, ultimately 
releasing viral genome into the host cytosol (Kumar et al. 2018; Plemper 2011). A culmination of the following steps results in direct translation of the genomic RNA to produce a polyprotein, which is cleaved by virus-derived and host-origin proteases to yield the multiple structural and nonstructural proteins (Fields et al. 2013). The structural features of the genomic RNA facilitating translation can be, e.g., a 5 'cap and a poly-A tail (Alphavirus, Togaviridae; Coronavirus, Coronaviridae) or a 5 'cap without a poly-A tail (Flavivirus, Flaviviridae) or an internal-ribosome entry site (IRES) serving for ribosome recruitment without a poly-A tail (hepatitis $\mathrm{C}$ virus) or an IRES with a poly-A tail (Picornaviridae, Astroviridae, Caliciviridae). After multiple rounds of translation, ribosome loading stops and the genomic RNA is replicated by virus-encoded RNA-dependent RNA polymerase (RdRp), in endoplasmic reticulum (ER) membrane-associated replication complexes (RCs) during which a double-stranded RNA intermediate is produced followed by its asymmetric transcription to produce multiple copies of plus-sense genomic RNA. The new genomic RNAs are packaged into virion particles that exit the cell by either secretory pathway or plasma-membrane budding (for enveloped viruses) or by cell lysis (for non-enveloped viruses) (Bird and Kirkegaard 2015; Pornillos et al. 2002).

\subsection{Infection, Intimation, and Initiation of Inflammation}

Although viruses can replicate in multiple types of cells, the pathological outcome manifests in only one or a few specific cell/tissue types. Independent of organismal entry site, the likeliest primary encounter of a virus is with mononuclear-phagocytic cells like monocytes, macrophages (M $\phi)$, and dendritic cells (DCs). $\mathrm{M} \phi$ and DCs are tissue-localized cells constituting the first line of cellular defense, which when infected can undertake antiviral steps in addition to "informing" the other effectors of the innate and adaptive immune system (Pohl et al. 2007; Ginhoux and Jung 2014). Activated DCs shift to lymph nodes, process viral antigen, and "present" or display it for clonal expansion of cognate lymphocytes population. $\mathrm{M} \phi$, which can be either tissue-resident or differentiated from afferent monocytes postinfection, play a more regulatory role and are important determinants of the outcome of the inflammatory response (Ginhoux and Jung 2014; Mercer and Greber 2013; Hou et al. 2012; Schulz et al. 2012). Tissue-resident $\mathrm{M} \phi$, which are a distinct population from monocyte-derived ones, include microglial cells in CNS, liver Kupffer cells, skin Langerhans cells, etc. (Davies et al. 2013)

Monocytes/M $\phi$ (and many other cell types) express molecular detector proteins called pattern recognition receptors (PRRs), specialized for interacting with signature motifs on microbe-derived molecules, termed as pathogen-associated molecular pattern (PAMP). Viral PAMPs include double-stranded (dsRNA) RNA (replication-intermediate formed during replication) and 5'-ppp (uncapped genomic RNA polymerized by de novo replication). Cellular PRRs specific for these include toll-like receptors (TLRs) like TLR3 (dsRNA) and RIG-I-like receptors (RLRs) like RIG-I, MDA5 (dsRNA, 5'-ppp end on RNA) (Jensen and Thomsen 2012). Nod-like receptors or NLRs form another class of cytosolic PRRs that can detect virus 
infection, albeit in an indirect manner (Takeuchi and Akira 2010; Ichinohe et al. 2013). Physical engagement with PAMPs activates the respective PRRs, stimulating alterations in conformation of these sensors that allow them to interact with adapter molecules mediating the assembly of multi-protein complexes called inflammosome, in parallel to activating the expression of cytokine genes coding for type-1 interferons (IFNs) and NFkB target genes (Kawai et al. 2005; Pichlmair and Reis e Sousa 2007; Chen and Ichinohe 2015; Seth et al. 2005). Secreted type-I IFNs attach specific receptors, in a paracrine or autocrine manner, thereby activating the expression of many interferon-sensitive genes (ISGs) with diverse functions that confer antiviral property to their activity (Schneider et al. 2014; Schoggins and Rice 2011). ISGs include PRR-coding genes producing a feed-forward loop and aggravating inflammation. In parallel, NFKB enhances expression of pro-inflammatory genes like TNF- $\alpha$, IL-1 $\beta$, COX2, IL6, IL-12p40, or IL-12 besides components of NLRP3 (Tak and Firestein 2001; Bauernfeind et al. 2009). Upon assembly the NLRP3 inflammosome catalyzes caspase-1 activation, a protease which slices the precursor form of pleiotropic pro-inflammatory cytokines like IL-1 $\beta$ and IL-18 generating their active secreted forms (Garlanda et al. 2013; Biet et al. 2002). IL-1 $\beta$ potentiates the antiviral response by multiple ways in addition to inducing expression of type-I IFNs and ISGs in DCs (Ben-Sasson et al. 2011; Aarreberg et al. 2018). Chemokines (chemotactic cytokines) flag/point to the site of infection by a concentration gradient, attracting leukocytes like neutrophils, monocytes, and lymphocytes, subsequently activating them to release more cytokines thereby amplifying the inflammatory response (Sokol and Luster 2015; Ley 2014). Among these IL-12 and IL-2 (produced predominantly by DCs) have crucial immunomodulatory functions. IL-12 attracts CD4+ T-helper (Th) cells influencing their differentiation into IFN- $\gamma$ secreting $\mathrm{Th}_{1}$ cells in addition to augmenting the cytotoxic activity of CD8+ T cells and NK cells (Athie-Morales et al. 2004; Henry et al. 2008). IL-2 on the other hand increases NK-cell sensitivity to IL-12 by receptor upregulation (Wang et al. 2000). IFN- $\gamma$ which in contrast to type-I IFNs is produced exclusively by immune cells ( $T$ and NK cells) has pleiotropic antiviral effect including the capacity to polarize existing or newly recruited M $\phi$ to M1 phenotype (Hu and Ivashkiv 2009; Verreck et al. 2004). Mф either resident or monocyte-derived can acquire either an M1 or an M2 phenotype differing in ontology, phenotype, and secretome, with unidirectional plasticity from M1 to M2 (Halstead et al. 2010; Guiducci et al. 2005; Smith et al. 2016). M1-M $\phi$ promotes a $\mathrm{Th}_{1}$ immune response which is necessary for resolution of infection, while the M2-M $\phi$ endorses tissue repair following inflammation, suggesting that a premature skew in abundance of $\mathrm{M} 2-\mathrm{M} \phi$ at the expense of M1-M $\phi$ would limit viral clearance leading to chronic infection and prolonged inflammatory response (Klenerman and Hill 2005). An emerging concept in modulation of inflammation involves the role of bacterial surface components like lipopolysaccharide on concurrent viral infection (Smith et al. 2016; Wilks and Golovkina 2012). Alterations in gut microbiome have been reported and potential influences this might have on disease outcome have been suggested (Preveden et al. 2017; Banks et al. 2015).

Though it is difficult to ascertain the number of asymptomatic infections for any given virus, the percentage of symptomatic infection vis-à-vis asymptomatic ones is 
often a multivariate variable, being known for only a few. For example, only 1 among 4 individuals infected with DENV shows febrile symptoms. This suggests a success for the antiviral immune mechanisms in the majority of individuals. Animal studies using gene knockout models have given evidence of this efficacy for many viruses (Suthar et al. 2010; Samuel and Diamond 2005; Lazear et al. 2011; Deonarain et al. 2004; Burdeinick-Kerr et al. 2007). In case of humans, these information are complicated by differential efficacy of these pathways, protecting or predisposing individuals under the influence of genotype, environment, etc. (Paalani et al. 2011; Mitchell and Aneshensel 2016; Liu and Taioli 2015) Besides, there are few studies that indicate potential influence of medication or noninfectious ailments or societal stress on the outcome of infection through an influence on the immune system (Mehrbod et al. 2014; Gilbert et al. 2005; Htun et al. 2015; Jean et al. 2007).

\subsubsection{Liver Damage Due to Hepatitis C Virus and Dengue Virus Infection}

HCV and DENV infection can cause liver damage through a chronic and acute infection regime, respectively (Samanta and Sharma 2015; Axley et al. 2018). Liver as an organ is characterized by a high capacity to regenerate; however, chronic injury/scarring can lead to fibrosis, steatosis, or even hepatocellular carcinoma resulting in liver failure (Forbes and Newsome 2016). Hepatocytes constitute twothirds of all liver cells and are associated with all major liver functions besides playing a crucial role in innate immune signaling (Kmiec 2001; Zhou et al. 2016). Hepatocytes are permissible to both $\mathrm{HCV}$ and DENV, the latter being reported to additionally infect Kupffer cells (Chang et al. 2003; Zehender et al. 1997; Boisvert et al. 2001; Caussin-Schwemling et al. 2001; Goutagny et al. 2003; Marianneau et al. 1999; de Macedo et al. 2006; Huerre et al. 2001). In acute infection, the major damage is through apoptosis following direct infection of these cells, whereas establishment of a chronic infection usually causes a sustained inflammation leading to infiltration of polymorphonuclear cells and lymphocytes (Huerre et al. 2001; Lim et al. 2014; Masalova et al. 2017; Deng et al. 2008; Bala et al. 2012; Sung et al. 2012). Irrespective of the virus, these infections augment PIC levels in the liver with drastic consequences. For example, hepatocyte apoptosis caused by either direct infection or effect of PICs like TNF- $\alpha$ generates apoptotic bodies which when engulfed by Kupffer cells induce the latter to release more PIC providing a positive loop toward inflammation (Canbay et al. 2003a; Burdette et al. 2012; Negash et al. 2013; Shimizu et al. 2005). Cytokines like TGF $\beta$ and PDGF thus released can "activate" hepatic stellate cells initiating a metabolic transformation in them to secrete more extracellular matrix that deposits as fibrotic tissue in addition to converting them into smooth muscle fibers (Canbay et al. 2003b; Hernandez-Gea and Friedman 2011). In addition to virus infection-induced changes, bacterial LPS can also potentially "activate" hepatic stellate cells (Brun et al. 2005). HCV infection skews macrophage population to M2 phenotype restraining virus clearance while promoting hepatic stellate cell activation mediated by TGF $\beta$ (Saha et al. 2016). Additionally, in 
case of infection by both of these viruses, immune suppression mediated by AIC like IL10 is implicated for virus persistence and augmented pathology (MacDonald et al. 2002; Sugimoto et al. 2003). In fact higher levels of cytokines like IL10 and IL17 have shown positive correlation with liver damage (Fernando et al. 2016). Liver steatosis, a clinical feature common among HCV patients, is the result of intracellular ROS in hepatocytes (Okuda et al. 2002; Perlemuter et al. 2002). Irrespective of the stimulus, a continuous cycle of injury and repair involving hepatocytes strongly prognoses the growth of hepatocellular carcinoma, DNA damage by augmented levels of ROS and RNS level playing a critical role (Bishayee 2014; Capone et al. 2010).

\subsubsection{CNS Damage Due to JEV, WNV, Zika Virus Infection, and Sometimes DENV Too}

The central nervous system (CNS) is physiologically isolated from the rest of the body by a specialized selectively permeable barricade called as the blood-brain barrier (BBB), which allows passage to selected metabolites, respiratory gases, and an extremely limited repertoire of circulatory tissue cells. This isolation is necessary for protection of low regeneration capacity neuronal cells from systemic inflammation, which can also upset the structural and functional plasticity of neurons that is dependent on cytokine signaling (Arnett et al. 2001; Gougeon et al. 2013; Mason et al. 2001; Fischer et al. 2011; Brissoni et al. 2006). The CNS can have either neuronal or non-neuronal glial cells; the latter provide vital functional support and include microglia (macrophage-like immune cells), oligodendrocytes (which provide insulation for neurons), and astrocytes (responsible for repair of damaged neuronal tissue). Microglial cells have immunomodulatory function in suppressing a pathogenic inflammation (Seitz et al. 2018). Multiple viruses in the +ve-ssRNA genome group, including Coronavirus, Picornavirus, Flaviviridae, and Togaviridae, cause opportunistic infection of CNS (Bergmann et al. 2006; Koyuncu et al. 2013; Fletcher and McKeating 2012).

In the absence of a direct admission route, these viruses undergo limited replication in peripheral tissue, before entering through either peripheral nerves or BBB microvasculature or CNS infiltrating leukocytes (functioning as the proverbial "Trojan horse") (Koyuncu et al. 2013; Jeha et al. 2003). A feature common here is a breach of the vascular endothelial barrier at varying locations, e.g., BBB for JEV/WNV, blood retinal barrier for ZIKV, and endothelial barriers in lungs/ peritoneum for DENV. Breach in BBB is more common for some viruses (e.g., WNV, JEV, ZIKAV, poliovirus) correlating with fatality. Interestingly, WNV and JEV have been suggested to cause BBB disruption from inside the CNS (Li et al. 2015; Verma et al. 2009). Still other reports suggest infected endothelial cells to secrete PICs that disrupt the BBB (Chen et al. 2014; Chang et al. 2017; Roach and Alcendor 2017). The tissue damage is caused from a combination of either direct neuronal infection which activates intrinsic apoptosis or a hyperactive inflammatory response mediated by PICs or CD8+ cytotoxic T cells (CTLs) (Wang et al. 
2003; Samuel et al. 2007). Infected neurons secrete chemokines that attract leukocytes like monocytes and lymphocytes (Klein et al. 2005; Shrestha and Diamond 2004; Glass et al. 2005; Kelley et al. 2003; Lim et al. 2011; Bardina et al. 2015; Durrant et al. 2015; Shrestha et al. 2008). The relation between a "good" and "bad" immune response is, however, very tricky when it comes to the CNS. Migration of CTLs expressing receptors for chemokines like CCL2, CCL3, CCL4, CCL5, CXCL9-11, as well as its timing with respect to establishment of infection, seems to play a crucial role in virus eradication and survival (Wang et al. 2003; Shrestha and Diamond 2004; Diamond et al. 2003; Sussman et al. 1989; Getts et al. 2010; Nansen et al. 2000; Chen et al. 2004; Liu et al. 2001; Zink et al. 2001; Winter et al. 2004). The CTLs exert their antiviral role by inducing cell death through either a perforin-dependent or Fas-FasL-mediated mechanism (Rossi et al. 1998; Shrestha and Diamond 2007). In addition to CTLs, other PICs might also induce direct cell death in neurons (Dhanwani et al. 2012; Olmo et al. 2017; Baer et al. 2016; Kumar et al. 2010).

\subsubsection{Dengue Infection-Associated Vascular Leakage}

Dengue virus causes a febrile illness with can turn fatal after a subsidence of the fever. The severity emanates from leakage of fluid from the blood vessels by a breach of the vascular endothelium. Circulating in four serotypes, severe disease is mostly associated with secondary infection by a serotype different from the one causing primary infection. Neutralizing antibodies generated during primary infection incompletely neutralize the secondary infection virus and instead promote their uptake by monocytes, by a phenomenon called antibody-dependent enhancement or ADE (Katzelnick et al. 2017; Dejnirattisai et al. 2016). Notwithstanding a primary or secondary infection, the pathological symptoms are considered to be the result of an unbridled host immune response (Basu and Chaturvedi 2008; Rothman 2011).

DENV infects a variety of cells including monocytes, dendritic cells (skin Langerhans cells), macrophages (Kupffer cells), and vascular endothelial cells, expectedly leading to PIC secretion (Wu et al. 2000; Jessie et al. 2004; Tolfvenstam et al. 2011). Different studies have reported a positive association of DHF/DSS development with extraordinarily augmented levels of different PICs that include macrophage migration inhibitory factor (MIF), IFN- $\alpha$, TNF- $\alpha$ (Green et al. 1999; Kurane et al. 1993; Huang et al. 2000; Chen et al. 2006). Although multiple reports have suggested correlation between specific PIC level and plasma leakage, the mechanism is still elusive and limited to association studies (Priyadarshini et al. 2010; Her et al. 2017; Sehrawat et al. 2018; Malavige et al. 2012). Interestingly however, multiple similar association studies have suggested a positive association between levels of IL10 (an AIC) and severe/critical symptoms related to dengue infection (Malavige et al. 2013; Tsai et al. 2013; Flores-Mendoza et al. 2017). IL10, produced by multiple immune cells, suppresses immune response through upregulation of SOCS (suppressor of cytokine signaling) function and downregulation of IFN activity, the result being decreased T-cell cytotoxicity (Halstead et al. 2010; 
Katzelnick et al. 2017; Tsai et al. 2013; Azeredo et al. 2001; Brasier et al. 2012). The augmentation of IL10 level has been suggested to emanate from monocytes infected by the ADE route with additional influence from high viremia (Tsai et al. 2014). IL10 is a dominant regulator of the immune system that can prolong pathogen clearance through a subversion of the immune response (Couper et al. 2008).

\subsubsection{Lung Infection and Pathology by Coronaviruses}

Coronavirus infections are usually benign causing self-limiting mild flu-like symptoms. However, recent outbreaks involving, e.g., severe acute respiratory syndrome coronavirus (SARS-CoV), which jumped species barrier through acquisition of minor genome mutations, have projected them as potentially severe human pathogens (Guan et al. 2004). Spread through aerosols, SARS-CoV primarily infect lung cells triggering an often fatal inflammatory response clinically called acute respiratory distress syndrome (ARDS) that starts with severe hypoxia, pulmonary edema progressing to systemic inflammation, and failure of multiple organs, culminating in high rate of mortality (Peiris et al. 2003; Lew et al. 2003; Tsushima et al. 2009; Farcas et al. 2005). Although evidence suggests that SARS-CoV can infect multiple cell types, lung type-II pneumocytes and ciliated epithelial cells constitute primary sites of virus replication, consequent to which these cells undergo apoptotic and/or necrotic death attracting innate immune cells and activating them to secrete PICs (Sims et al. 2005; Chow et al. 2004; Nicholls et al. 2003). The nature of inflammation following SARS-CoV infection is characterized by a prompt production of PICs through immediate NFKB activation and a delayed expression of type-I IFN genes (Shi et al. 2014; Kong et al. 2009; Wong et al. 2004). Severity of symptoms correlates positively with IL-6 levels while exhibiting negative correlation with that of IL-8 and TGF $\beta$ (Zhang et al. 2004). As observed with many other viral pathogenesis models, macrophage polarization culminating in preferential enrichment of M2-macrophages has been suggested to be responsible for SARS-CoV pathogenesis (Page et al. 2012). SARS-CoV infection is also associated with hemophagocytosis or engulfment of different types of blood cells by histiocytes (a class within macrophages), which is a clinical marker of immune system hyper-activation (Usmani et al. 2013).

\subsection{Therapeutic Approaches Using Cytokine}

Traditionally prophylactic or therapeutic strategies for combating viral pathogenesis are designed using vaccines or directly acting antivirals (DAA), respectively. But for many viruses there is no clinically approved product to serve in either approach. Since the etiology of critical pathogenic symptoms is often associated with an unbridled host inflammatory response, there have been suggestions and attempts to control the harmful effects through modulation of key inflammatory signaling (D'Elia et al. 2013). However, a holistic approach to complete "cure" should 
probably involve investigations to provide support to both approaches simultaneously. Only ribavirin or the same combined with pegylated IFN- $\alpha$ was the therapeutic strategy for controlling HCV infection, before the advent of high efficacy DAAs. Similarly IFN- $\lambda$ and glucocorticoids, both of which can consolidate the BBB, have been suggested as therapeutics for combating viral diseases that disrupt this barrier (Rhen and Cidlowski 2005; Daniels et al. 2014; Lazear et al. 2015; Wang et al. 2004; Blecharz et al. 2010; Fabene et al. 2008). Likewise, administration of PICs like CCL7 and IL17A has shown efficacy in increasing survival of mice experimentally infected with WNV (Bardina et al. 2015; Acharya et al. 2016). In dengue patients, however, meddling with either promoter or inhibitor of inflammation has been suggested as possible approaches (Tsai et al. 2013; Goh et al. 2014; Callaway et al. 2015; Ji et al. 2005; Dinarello 2011). Small molecules that can influence the function of the NLRP3 inflammosome have also been projected as potential therapies for CHIKV and can be tested against dengue as well (Chen et al. 2017; Coll et al. 2015; Hottz et al. 2013). Alternative approaches using pharmaceuticals that indirectly mitigate the pathological effect without interfering with inflammation have also been discussed (Olmo et al. 2017; Grip and Janciauskiene 2009; Reynolds and Miller 1989; Thomas and Grossberg 2009; Giguere and Tremblay 2004; Raemer et al. 2009).

\subsection{Concluding Remarks}

An ability to suppress innate immunity pathways is common among viruses that cause severe human diseases. Nonetheless modulating inflammation needs extreme caution, in order to reduce potential cytotoxicity of the administered therapeutic. Therefore, there is a need to go beyond association studies to generate a clearer picture of the exact role that inflammation plays in viral pathology, which can then assist in developing therapeutic strategies that tinker with inflammation.

Conflict of Interest The author declares that they have no competing interests.

\section{References}

Aarreberg LD et al (2018) Interleukin-1beta signaling in dendritic cells induces antiviral interferon responses. MBio 9. ). pii: e00342-18.

Acharya D et al (2016) Interleukin-17A promotes CD8+ T cell cytotoxicity to facilitate West Nile virus clearance. J Virol 91:e01529

Arnett HA et al (2001) TNF alpha promotes proliferation of oligodendrocyte progenitors and remyelination. Nat Neurosci 4:1116-1122

Athie-Morales V, Smits HH, Cantrell DA, Hilkens CM (2004) Sustained IL-12 signaling is required for Th1 development. J Immunol 172:61-69

Axley P, Ahmed Z, Ravi S, Singal AK (2018) Hepatitis C virus and hepatocellular carcinoma: a narrative review. J Clin Transl Hepatol 6:79-84 
Azeredo EL et al (2001) Characterisation of lymphocyte response and cytokine patterns in patients with dengue fever. Immunobiology 204:494-507

Baer A et al (2016) Venezuelan equine encephalitis virus induces apoptosis through the unfolded protein response activation of EGR1. J Virol 90:3558-3572

Bala $S$ et al (2012) Increased microRNA-155 expression in the serum and peripheral monocytes in chronic HCV infection. J Transl Med 10:151

Banks WA et al (2015) Lipopolysaccharide-induced blood-brain barrier disruption: roles of cyclooxygenase, oxidative stress, neuroinflammation, and elements of the neurovascular unit. J Neuroinflammation 12:223

Bardina SV et al (2015) Differential roles of chemokines CCL2 and CCL7 in monocytosis and leukocyte migration during West Nile virus infection. J Immunol 195:4306-4318

Basu A, Chaturvedi UC (2008) Vascular endothelium: the battlefield of dengue viruses. FEMS Immunol Med Microbiol 53:287-299

Bauernfeind FG et al (2009) Cutting edge: NF-kappaB activating pattern recognition and cytokine receptors license NLRP3 inflammasome activation by regulating NLRP3 expression. J Immunol 183:787-791

Ben-Sasson SZ, Caucheteux S, Crank M, Hu-Li J, Paul WE (2011) IL-1 acts on T cells to enhance the magnitude of in vivo immune responses. Cytokine 56:122-125

Bergmann CC, Lane TE, Stohlman SA (2006) Coronavirus infection of the central nervous system: host-virus stand-off. Nat Rev Microbiol 4:121-132

Biet F, Locht C, Kremer L (2002) Immunoregulatory functions of interleukin 18 and its role in defense against bacterial pathogens. J Mol Med (Berl) 80:147-162

Bird SW, Kirkegaard K (2015) Escape of non-enveloped virus from intact cells. Virology 479-480:444-449

Bishayee A (2014) The role of inflammation and liver cancer. Adv Exp Med Biol 816:401-435

Blecharz KG et al (2010) Glucocorticoid effects on endothelial barrier function in the murine brain endothelial cell line cEND incubated with sera from patients with multiple sclerosis. Mult Scler 16:293-302

Boisvert J et al (2001) Quantitative analysis of hepatitis C virus in peripheral blood and liver: replication detected only in liver. J Infect Dis 184:827-835

Brasier AR et al (2012) A three-component biomarker panel for prediction of dengue hemorrhagic fever. Am J Trop Med Hyg 86:341-348

Brissoni B et al (2006) Intracellular trafficking of interleukin-1 receptor I requires Tollip. Curr Biol 16:2265-2270

Brun P, Castagliuolo I, Pinzani M, Palu G, Martines D (2005) Exposure to bacterial cell wall products triggers an inflammatory phenotype in hepatic stellate cells. Am J Physiol Gastrointest Liver Physiol 289:G571-G578

Burdeinick-Kerr R, Wind J, Griffin DE (2007) Synergistic roles of antibody and interferon in noncytolytic clearance of Sindbis virus from different regions of the central nervous system. J Virol 81:5628-5636

Burdette D et al (2012) Hepatitis C virus activates interleukin-1beta via caspase-1-inflammasome complex. J Gen Virol 93:235-246

Callaway JB et al (2015) Spleen tyrosine kinase (Syk) mediates IL-1beta induction by primary human monocytes during antibody-enhanced dengue virus infection. J Biol Chem 290:17306-17320

Canbay A et al (2003a) Kupffer cell engulfment of apoptotic bodies stimulates death ligand and cytokine expression. Hepatology 38:1188-1198

Canbay A et al (2003b) Apoptotic body engulfment by a human stellate cell line is profibrogenic. Lab Investig 83:655-663

Capone $\mathrm{F}$ et al (2010) Serum cytokine levels in patients with hepatocellular carcinoma. Eur Cytokine Netw 21:99-104

Caussin-Schwemling C, Schmitt C, Stoll-Keller F (2001) Study of the infection of human blood derived monocyte/macrophages with hepatitis $\mathrm{C}$ virus in vitro. J Med Virol 65:14-22 
Chang M et al (2003) Dynamics of hepatitis C virus replication in human liver. Am J Pathol $163: 433-444$

Chang CY et al (2017) Interplay of inflammatory gene expression in pericytes following Japanese encephalitis virus infection. Brain Behav Immun 66:230-243

Chen IY, Ichinohe T (2015) Response of host inflammasomes to viral infection. Trends Microbiol 23:55-63

Chen Y et al (1997) Dengue virus infectivity depends on envelope protein binding to target cell heparan sulfate. Nat Med 3:866-871

Chen CJ, Chen JH, Chen SY, Liao SL, Raung SL (2004) Upregulation of RANTES gene expression in neuroglia by Japanese encephalitis virus infection. J Virol 78:12107-12119

Chen LC et al (2006) Correlation of serum levels of macrophage migration inhibitory factor with disease severity and clinical outcome in dengue patients. Am J Trop Med Hyg 74:142-147

Chen CJ et al (2014) Infection of pericytes in vitro by Japanese encephalitis virus disrupts the integrity of the endothelial barrier. J Virol 88:1150-1161

Chen W et al (2017) Specific inhibition of NLRP3 in chikungunya disease reveals a role for inflammasomes in alphavirus-induced inflammation. Nat Microbiol 2:1435-1445

Chow KC, Hsiao CH, Lin TY, Chen CL, Chiou SH (2004) Detection of severe acute respiratory syndrome-associated coronavirus in pneumocytes of the lung. Am J Clin Pathol 121:574-580

Coll RC et al (2015) A small-molecule inhibitor of the NLRP3 inflammasome for the treatment of inflammatory diseases. Nat Med 21:248-255

Couper KN, Blount DG, Riley EM (2008) IL-10: the master regulator of immunity to infection. J Immunol 180:5771-5777

Daniels BP et al (2014) Viral pathogen-associated molecular patterns regulate blood-brain barrier integrity via competing innate cytokine signals. MBio 5:e01476-e01414

Davies LC, Jenkins SJ, Allen JE, Taylor PR (2013) Tissue-resident macrophages. Nat Immunol 14:986-995

de Macedo FC et al (2006) Histologic, viral, and molecular correlates of dengue fever infection of the liver using highly sensitive immunohistochemistry. Diagn Mol Pathol 15:223-228

Dejnirattisai W et al (2016) Dengue virus sero-cross-reactivity drives antibody-dependent enhancement of infection with zika virus. Nat Immunol 17:1102-1108

D'Elia RV, Harrison K, Oyston PC, Lukaszewski RA, Clark GC (2013) Targeting the "cytokine storm" for therapeutic benefit. Clin Vaccine Immunol 20:319-327

Deng L et al (2008) Hepatitis $\mathrm{C}$ virus infection induces apoptosis through a Bax-triggered, mitochondrion-mediated, caspase 3-dependent pathway. J Virol 82:10375-10385

Deonarain R, Cerullo D, Fuse K, Liu PP, Fish EN (2004) Protective role for interferon-beta in coxsackievirus B3 infection. Circulation 110:3540-3543

Dhanwani R et al (2012) Characterization of Chikungunya virus infection in human neuroblastoma SH-SY5Y cells: role of apoptosis in neuronal cell death. Virus Res 163:563-572

Diamond MS, Shrestha B, Mehlhop E, Sitati E, Engle M (2003) Innate and adaptive immune responses determine protection against disseminated infection by West Nile encephalitis virus. Viral Immunol 16:259-278

Dinarello CA (2011) Blocking interleukin-1beta in acute and chronic autoinflammatory diseases. J Intern Med 269:16-28

Durrant DM, Daniels BP, Pasieka T, Dorsey D, Klein RS (2015) CCR5 limits cortical viral loads during West Nile virus infection of the central nervous system. J Neuroinflammation 12:233

Fabene PF et al (2008) A role for leukocyte-endothelial adhesion mechanisms in epilepsy. Nat Med 14:1377-1383

Farcas GA et al (2005) Fatal severe acute respiratory syndrome is associated with multiorgan involvement by coronavirus. J Infect Dis 191:193-197

Fernando S et al (2016) Patterns and causes of liver involvement in acute dengue infection. BMC Infect Dis 16:319

Fields BN, Knipe DM, Howley PM (2013) In: Knipe DM, Howley PM, Cohen JI et al (eds) Fields virology, 6th edn. Wolters Kluwer Health/Lippincott Williams \& Wilkins, Philadelphia 
Fischer R et al (2011) Ligand-induced internalization of TNF receptor 2 mediated by a di-leucin motif is dispensable for activation of the NFkappaB pathway. Cell Signal 23:161-170

Fletcher NF, McKeating JA (2012) Hepatitis C virus and the brain. J Viral Hepat 19:301-306

Flores-Mendoza LK et al (2017) IL-10 and socs3 are predictive biomarkers of dengue hemorrhagic fever. Mediat Inflamm 2017(5197592):1

Forbes SJ, Newsome PN (2016) Liver regeneration - mechanisms and models to clinical application. Nat Rev Gastroenterol Hepatol 13:473-485

Garlanda C, Dinarello CA, Mantovani A (2013) The interleukin-1 family: back to the future. Immunity 39:1003-1018

Getts MT, Richards MH, Miller SD (2010) A critical role for virus-specific CD8(+) CTLs in protection from Theiler's virus-induced demyelination in disease-susceptible SJL mice. Virology 402:102-111

Giguere JF, Tremblay MJ (2004) Statin compounds reduce human immunodeficiency virus type 1 replication by preventing the interaction between virion-associated host intercellular adhesion molecule 1 and its natural cell surface ligand LFA-1. J Virol 78:12062-12065

Gilbert C, Bergeron M, Methot S, Giguere JF, Tremblay MJ (2005) Statins could be used to control replication of some viruses, including HIV-1. Viral Immunol 18:474-489

Ginhoux F, Jung S (2014) Monocytes and macrophages: developmental pathways and tissue homeostasis. Nat Rev Immunol 14:392-404

Glass WG et al (2005) Chemokine receptor CCR5 promotes leukocyte trafficking to the brain and survival in West Nile virus infection. J Exp Med 202:1087-1098

Goh AX et al (2014) A novel human anti-interleukin-1beta neutralizing monoclonal antibody showing in vivo efficacy. MAbs 6:765-773

Gougeon PY et al (2013) The pro-inflammatory cytokines IL-1beta and TNFalpha are neurotrophic for enteric neurons. J Neurosci 33:3339-3351

Goutagny N et al (2003) Evidence of viral replication in circulating dendritic cells during hepatitis C virus infection. J Infect Dis 187:1951-1958

Green S et al (1999) Early immune activation in acute dengue illness is related to development of plasma leakage and disease severity. J Infect Dis 179:755-762

Grip O, Janciauskiene S (2009) Atorvastatin reduces plasma levels of chemokine (CXCL10) in patients with Crohn's disease. PLoS One 4:e5263

Guan Y et al (2004) Molecular epidemiology of the novel coronavirus that causes severe acute respiratory syndrome. Lancet 363:99-104

Guiducci C, Vicari AP, Sangaletti S, Trinchieri G, Colombo MP (2005) Redirecting in vivo elicited tumor infiltrating macrophages and dendritic cells towards tumor rejection. Cancer Res 65:3437-3446

Halstead SB, Mahalingam S, Marovich MA, Ubol S, Mosser DM (2010) Intrinsic antibodydependent enhancement of microbial infection in macrophages: disease regulation by immune complexes. Lancet Infect Dis 10:712-722

Henry CJ, Ornelles DA, Mitchell LM, Brzoza-Lewis KL, Hiltbold EM (2008) IL-12 produced by dendritic cells augments CD8+ T cell activation through the production of the chemokines CCL1 and CCL17. J Immunol 181:8576-8584

Her $\mathrm{Z}$ et al (2017) Severity of plasma leakage is associated with high levels of interferon gammainducible protein 10, hepatocyte growth factor, matrix metalloproteinase 2 (MMP-2), and MMP-9 during dengue virus infection. J Infect Dis 215:42-51

Hernandez-Gea V, Friedman SL (2011) Pathogenesis of liver fibrosis. Annu Rev Pathol 6:425-456

Hottz ED et al (2013) Platelets mediate increased endothelium permeability in dengue through NLRP3-inflammasome activation. Blood 122:3405-3414

Hou W et al (2012) Viral infection triggers rapid differentiation of human blood monocytes into dendritic cells. Blood 119:3128-3131

Htun NS et al (2015) Is diabetes a risk factor for a severe clinical presentation of dengue?--review and meta-analysis. PLoS Negl Trop Dis 9:e0003741

Hu X, Ivashkiv LB (2009) Cross-regulation of signaling pathways by interferon-gamma: implications for immune responses and autoimmune diseases. Immunity 31:539-550 
Huang YH et al (2000) Dengue virus infects human endothelial cells and induces IL-6 and IL-8 production. Am J Trop Med Hyg 63:71-75

Huerre MR et al (2001) Liver histopathology and biological correlates in five cases of fatal dengue fever in Vietnamese children. Virchows Arch 438:107-115

Ichinohe T, Yamazaki T, Koshiba T, Yanagi Y (2013) Mitochondrial protein mitofusin 2 is required for NLRP3 inflammasome activation after RNA virus infection. Proc Natl Acad Sci U S A 110:17963-17968

Jean CM, Honarmand S, Louie JK, Glaser CA (2007) Risk factors for West Nile virus neuroinvasive disease, California, 2005. Emerg Infect Dis 13:1918-1920

Jeha LE et al (2003) West Nile virus infection: a new acute paralytic illness. Neurology 61:55-59

Jensen S, Thomsen AR (2012) Sensing of RNA viruses: a review of innate immune receptors involved in recognizing RNA virus invasion. J Virol 86:2900-2910

Jessie K, Fong MY, Devi S, Lam SK, Wong KT (2004) Localization of dengue virus in naturally infected human tissues, by immunohistochemistry and in situ hybridization. J Infect Dis 189:1411-1418

Ji JD et al (2005) Inhibition of IL-10-induced STAT3 activation by 15-deoxy-Delta12,14prostaglandin J2. Rheumatology (Oxford) 44:983-988

Katzelnick LC et al (2017) Antibody-dependent enhancement of severe dengue disease in humans. Science 358:929-932

Kawai $\mathrm{T}$ et al (2005) IPS-1, an adaptor triggering RIG-I- and Mda5-mediated type I interferon induction. Nat Immunol 6:981-988

Kelley TW, Prayson RA, Ruiz AI, Isada CM, Gordon SM (2003) The neuropathology of West Nile virus meningoencephalitis. A report of two cases and review of the literature. Am J Clin Pathol 119:749-753

Klein RS et al (2005) Neuronal CXCL10 directs CD8+ T-cell recruitment and control of West Nile virus encephalitis. J Virol 79:11457-11466

Klenerman P, Hill A (2005) T cells and viral persistence: lessons from diverse infections. Nat Immunol 6:873-879

Kmiec Z (2001) Cooperation of liver cells in health and disease. In: Advances in anatomy, embryology and cell biology, vol 161. Springer, Berlin, pp 1-151

Kong SL, Chui P, Lim B, Salto-Tellez M (2009) Elucidating the molecular physiopathology of acute respiratory distress syndrome in severe acute respiratory syndrome patients. Virus Res 145:260-269

Koyuncu OO, Hogue IB, Enquist LW (2013) Virus infections in the nervous system. Cell Host Microbe 13:379-393

Kumar M, Verma S, Nerurkar VR (2010) Pro-inflammatory cytokines derived from West Nile virus (WNV)-infected SK-N-SH cells mediate neuroinflammatory markers and neuronal death. J Neuroinflammation 7:73

Kumar CS, Dey D, Ghosh S, Banerjee M (2018) Breach: host membrane penetration and entry by nonenveloped viruses. Trends Microbiol 26:525-537

Kurane I et al (1993) High levels of interferon alpha in the sera of children with dengue virus infection. Am J Trop Med Hyg 48:222-229

Lazear HM, Pinto AK, Vogt MR, Gale M Jr, Diamond MS (2011) Beta interferon controls West Nile virus infection and pathogenesis in mice. J Virol 85:7186-7194

Lazear HM et al (2015) Interferon-lambda restricts West Nile virus neuroinvasion by tightening the blood-brain barrier. Sci Transl Med 7:284ra59

Lew TW et al (2003) Acute respiratory distress syndrome in critically ill patients with severe acute respiratory syndrome. JAMA 290:374-380

Ley K (2014) The second touch hypothesis: T cell activation, homing and polarization. F1000Res $3: 37$

Li F et al (2015) Viral infection of the central nervous system and neuroinflammation precede bloodbrain barrier disruption during Japanese encephalitis virus infection. J Virol 89:5602-5614

Lim JK et al (2011) Chemokine receptor Ccr2 is critical for monocyte accumulation and survival in West Nile virus encephalitis. J Immunol 186:471-478 
Lim EJ et al (2014) Hepatitis C virus-induced hepatocyte cell death and protection by inhibition of apoptosis. J Gen Virol 95:2204-2215

Liu B, Taioli E (2015) Seasonal variations of complete blood count and inflammatory biomarkers in the US population - analysis of NHANES data. PLoS One 10:e142382

Liu MT, Armstrong D, Hamilton TA, Lane TE (2001) Expression of Mig (monokine induced by interferon-gamma) is important in $\mathrm{T}$ lymphocyte recruitment and host defense following viral infection of the central nervous system. J Immunol 166:1790-1795

MacDonald AJ et al (2002) CD4 T helper type 1 and regulatory T cells induced against the same epitopes on the core protein in hepatitis C virus-infected persons. J Infect Dis 185:720-727

Malavige GN et al (2012) Cellular and cytokine correlates of severe dengue infection. PLoS One 7:e50387

Malavige GN et al (2013) Serum IL-10 as a marker of severe dengue infection. BMC Infect Dis $13: 341$

Marianneau P et al (1999) Infection of primary cultures of human Kupffer cells by dengue virus: no viral progeny synthesis, but cytokine production is evident. J Virol 73:5201-5206

Masalova OV et al (2017) Modulation of Cell Death Pathways by Hepatitis C Virus Proteins in Huh7.5 Hepatoma Cells. Int J Mol Sci 18:E2346

Mason JL, Suzuki K, Chaplin DD, Matsushima GK (2001) Interleukin-1beta promotes repair of the CNS. J Neurosci 21:7046-7052

Mehrbod P, Omar AR, Hair-Bejo M, Haghani A, Ideris A (2014) Mechanisms of action and efficacy of statins against influenza. Biomed Res Int 2014(872370):1

Mercer J, Greber UF (2013) Virus interactions with endocytic pathways in macrophages and dendritic cells. Trends Microbiol 21:380-388

Mitchell UA, Aneshensel CS (2016) Social inequalities in inflammation. J Aging Health 29:769-787

Nansen A, Marker O, Bartholdy C, Thomsen AR (2000) CCR2+ and CCR5+ CD8+ T cells increase during viral infection and migrate to sites of infection. Eur J Immunol 30:1797-1806

Negash AA et al (2013) IL-1beta production through the NLRP3 inflammasome by hepatic macrophages links hepatitis $\mathrm{C}$ virus infection with liver inflammation and disease. PLoS Pathog 9:e1003330

Nicholls JM et al (2003) Lung pathology of fatal severe acute respiratory syndrome. Lancet 361:1773-1778

Okuda M et al (2002) Mitochondrial injury, oxidative stress, and antioxidant gene expression are induced by hepatitis $C$ virus core protein. Gastroenterology 122:366-375

Olenina LV et al (2005) Identification of glycosaminoglycan-binding sites within hepatitis C virus envelope glycoprotein E2*. J Viral Hepat 12:584-593

Olmo IG et al (2017) Zika virus promotes neuronal cell death in a non-cell autonomous manner by triggering the release of neurotoxic factors. Front Immunol 8:1016

Paalani M, Lee JW, Haddad E, Tonstad S (2011) Determinants of inflammatory markers in a biethnic population. Ethn Dis 21:142-149

Page $\mathrm{C}$ et al (2012) Induction of alternatively activated macrophages enhances pathogenesis during severe acute respiratory syndrome coronavirus infection. J Virol 86:13334-13349

Peiris JS, Yuen KY, Osterhaus AD, Stohr K (2003) The severe acute respiratory syndrome. N Engl J Med 349:2431-2441

Perlemuter G et al (2002) Hepatitis C virus core protein inhibits microsomal triglyceride transfer protein activity and very low density lipoprotein secretion: a model of viral-related steatosis. FASEB J 16:185-194

Pichlmair A, Reis e Sousa C (2007) Innate recognition of viruses. Immunity 27:370-383

Plemper RK (2011) Cell entry of enveloped viruses. Curr Opin Virol 1:92-100

Pohl C, Shishkova J, Schneider-Schaulies S (2007) Viruses and dendritic cells: enemy mine. Cell Microbiol 9:279-289

Pornillos O, Garrus JE, Sundquist WI (2002) Mechanisms of enveloped RNA virus budding. Trends Cell Biol 12:569-579 
Preveden T, Scarpellini E, Milic N, Luzza F, Abenavoli L (2017) Gut microbiota changes and chronic hepatitis C virus infection. Expert Rev Gastroenterol Hepatol 11:813-819

Priyadarshini D et al (2010) Clinical findings and pro-inflammatory cytokines in dengue patients in Western India: a facility-based study. PLoS One 5:e8709

Raemer PC, Kohl K, Watzl C (2009) Statins inhibit NK-cell cytotoxicity by interfering with LFA1-mediated conjugate formation. Eur J Immunol 39:1456-1465

Reynolds IJ, Miller RJ (1989) Ifenprodil is a novel type of N-methyl-D-aspartate receptor antagonist: interaction with polyamines. Mol Pharmacol 36:758-765

Rhen T, Cidlowski JA (2005) Antiinflammatory action of glucocorticoids--new mechanisms for old drugs. N Engl J Med 353:1711-1723

Roach T, Alcendor DJ (2017) Zika virus infection of cellular components of the blood-retinal barriers: implications for viral associated congenital ocular disease. J Neuroinflammation 14:43

Rossi CP, McAllister A, Tanguy M, Kagi D, Brahic M (1998) Theiler's virus infection of perforindeficient mice. J Virol 72:4515-4519

Rothman AL (2011) Immunity to dengue virus: a tale of original antigenic sin and tropical cytokine storms. Nat Rev Immunol 11:532-543

Saha B, Kodys K, Szabo G (2016) Hepatitis C virus-induced monocyte differentiation into polarized M2 macrophages promotes stellate cell activation via TGF-beta. Cell Mol Gastroenterol Hepatol 2:302-316.e8

Samanta J, Sharma V (2015) Dengue and its effects on liver. World J Clin Cases 3:125-131

Samuel MA, Diamond MS (2005) Alpha/beta interferon protects against lethal West Nile virus infection by restricting cellular tropism and enhancing neuronal survival. J Virol 79:13350-13361

Samuel MA, Morrey JD, Diamond MS (2007) Caspase 3-dependent cell death of neurons contributes to the pathogenesis of West Nile virus encephalitis. J Virol 81:2614-2623

Scarpellini E et al (2015) The human gut microbiota and virome: potential therapeutic implications. Dig Liver Dis 47:1007-1012

Schneider WM, Chevillotte MD, Rice CM (2014) Interferon-stimulated genes: a complex web of host defenses. Annu Rev Immunol 32:513-545

Schoggins JW, Rice CM (2011) Interferon-stimulated genes and their antiviral effector functions. Curr Opin Virol 1:519-525

Schulz C et al (2012) A lineage of myeloid cells independent of Myb and hematopoietic stem cells. Science 336:86-90

Sehrawat P et al (2018) Role of cytokines as molecular marker of dengue severity. Mediterr J Hematol Infect Dis 10:e2018023

Seitz S, Clarke P, Tyler KL (2018) Pharmacologic depletion of microglia increases viral load in the brain and enhances mortality in murine models of flavivirus-induced encephalitis. J Virol 92:e00525

Seth RB, Sun L, Ea CK, Chen ZJ (2005) Identification and characterization of MAVS, a mitochondrial antiviral signaling protein that activates NF-kappaB and IRF 3. Cell 122:669-682

Shi CS et al (2014) SARS-coronavirus open reading frame-9b suppresses innate immunity by targeting mitochondria and the MAVS/TRAF3/TRAF6 signalosome. J Immunol 193:3080-3089

Shimizu S et al (2005) Liver injury induced by lipopolysaccharide is mediated by TNFR-1 but not by TNFR-2 or Fas in mice. Hepatol Res 31:136-142

Shrestha B, Diamond MS (2004) Role of CD8+ T cells in control of West Nile virus infection. J Virol 78:8312-8321

Shrestha B, Diamond MS (2007) Fas ligand interactions contribute to CD8+ T-cell-mediated control of West Nile virus infection in the central nervous system. J Virol 81:11749-11757

Shrestha B, Zhang B, Purtha WE, Klein RS, Diamond MS (2008) Tumor necrosis factor alpha protects against lethal West Nile virus infection by promoting trafficking of mononuclear leukocytes into the central nervous system. J Virol 82:8956-8964

Sims AC et al (2005) Severe acute respiratory syndrome coronavirus infection of human ciliated airway epithelia: role of ciliated cells in viral spread in the conducting airways of the lungs. $\mathrm{J}$ Virol 79:15511-15524 
Smith TD, Tse MJ, Read EL, Liu WF (2016) Regulation of macrophage polarization and plasticity by complex activation signals. Integr Biol (Camb) 8:946-955

Sokol CL, Luster AD (2015) The chemokine system in innate immunity. Cold Spring Harb Perspect Biol 7. pii: a016303.

Sugimoto K et al (2003) Suppression of HCV-specific T cells without differential hierarchy demonstrated ex vivo in persistent HCV infection. Hepatology 38:1437-1448

Sung JM, Lee CK, Wu-Hsieh BA (2012) Intrahepatic infiltrating NK and CD8 T cells cause liver cell death in different phases of dengue virus infection. PLoS One 7:e46292

Sussman MA, Shubin RA, Kyuwa S, Stohlman SA (1989) T-cell-mediated clearance of mouse hepatitis virus strain JHM from the central nervous system. J Virol 63:3051-3056

Suthar MS et al (2010) IPS-1 is essential for the control of West Nile virus infection and immunity. PLoS Pathog 6:e1000757

Tak PP, Firestein GS (2001) NF-kappaB: a key role in inflammatory diseases. J Clin Invest 107:7-11

Takeuchi O, Akira S (2010) Pattern recognition receptors and inflammation. Cell 140:805-820

Tan CW, Poh CL, Sam IC, Chan YF (2013) Enterovirus 71 uses cell surface heparan sulfate glycosaminoglycan as an attachment receptor. J Virol 87:611-620

Thomas SJ, Grossberg GT (2009) Memantine: a review of studies into its safety and efficacy in treating Alzheimer's disease and other dementias. Clin Interv Aging 4:367-377

Tolfvenstam $\mathrm{T}$ et al (2011) Characterization of early host responses in adults with dengue disease. BMC Infect Dis 11:209

Tsai TT et al (2013) An emerging role for the anti-inflammatory cytokine interleukin-10 in dengue virus infection. J Biomed Sci 20:40

Tsai TT et al (2014) Antibody-dependent enhancement infection facilitates dengue virus-regulated signaling of IL-10 production in monocytes. PLoS Negl Trop Dis 8:e3320

Tsushima K et al (2009) Acute lung injury review. Intern Med 48:621-630

Turner MD, Nedjai B, Hurst T, Pennington DJ (2014) Cytokines and chemokines: at the crossroads of cell signalling and inflammatory disease. Biochim Biophys Acta 1843:2563-2582

Usmani GN, Woda BA, Newburger PE (2013) Advances in understanding the pathogenesis of HLH. Br J Haematol 161:609-622

Verma S et al (2009) West Nile virus infection modulates human brain microvascular endothelial cells tight junction proteins and cell adhesion molecules: transmigration across the in vitro blood-brain barrier. Virology 385:425-433

Verreck FA et al (2004) Human IL-23-producing type 1 macrophages promote but IL-10producing type 2 macrophages subvert immunity to (myco)bacteria. Proc Natl Acad Sci U S A 101:4560-4565

Wang KS, Frank DA, Ritz J (2000) Interleukin-2 enhances the response of natural killer cells to interleukin-12 through up-regulation of the interleukin-12 receptor and STAT4. Blood 95:3183-3190

Wang Y, Lobigs M, Lee E, Mullbacher A (2003) CD8+ T cells mediate recovery and immunopathology in West Nile virus encephalitis. J Virol 77:13323-13334

Wang T et al (2004) Toll-like receptor 3 mediates West Nile virus entry into the brain causing lethal encephalitis. Nat Med 10:1366-1373

Wilks J, Golovkina T (2012) Influence of microbiota on viral infections. PLoS Pathog 8:e1002681

Winter PM et al (2004) Proinflammatory cytokines and chemokines in humans with Japanese encephalitis. J Infect Dis 190:1618-1626

Wong CK et al (2004) Plasma inflammatory cytokines and chemokines in severe acute respiratory syndrome. Clin Exp Immunol 136:95-103

Wu SJ et al (2000) Human skin Langerhans cells are targets of dengue virus infection. Nat Med 6:816-820

Zehender G et al (1997) Detection of hepatitis C virus RNA in CD19 peripheral blood mononuclear cells of chronically infected patients. J Infect Dis 176:1209-1214 
Zhang Y et al (2004) Analysis of serum cytokines in patients with severe acute respiratory syndrome. Infect Immun 72:4410-4415

Zhou Z, Xu MJ, Gao B (2016) Hepatocytes: a key cell type for innate immunity. Cell Mol Immunol 13:301-315

Zink MC et al (2001) Increased macrophage chemoattractant protein-1 in cerebrospinal fluid precedes and predicts simian immunodeficiency virus encephalitis. J Infect Dis 184:1015-1021 